\title{
Study of Potential of Marine Macroalgae Biochar for Acid Dyes Removal
}

\author{
KARISHMA D. SHAH ${ }^{1}$, NAYANA H. BRAHMBHATT ${ }^{1 *}$ and POOJA N. THAKER ${ }^{1}$ \\ Department of Biology, V. P. Science College, Sardar Patel University, Vallabh Vidhyanagar-388120, \\ Gujarat, India. \\ *Corresponding author E-mail: naina_bbhatt@yahoo.co.in \\ http://dx.doi.org/10.13005/ojc/370620
}

(Received: September 25, 2021; Accepted: November 11, 2021)

\begin{abstract}
The goal of this investigation was to check the feasibility of Ulva lactuca carbon could be used to adsorb acid yellow 19 dyes from an aqueous solution. A series of studies were carried out to determine the best conditions for acid dye adsorption. 90 percent colour removal was achieved when $\mathrm{pH} 3,1 \mathrm{~g}$ dose, $100 \mathrm{mg} / \mathrm{L}$ dye concentration were used for dye adsorption. During the analysis, it was discovered that as the carbon dose was raised, the dye elimination rate rose. The main objective of this study is to reduce solid waste disposal while also addressing the issue of seaweed and developing an effective plan.
\end{abstract}

Keywords: Dye adsorption, Seaweed biochar, Economic Method, Water reuse approach.

\section{INTRODUCTION}

Dyes are generally more stable and difficult to degrade because of their complex aromatic structure. ${ }^{1}$ Dyes are used widely in various industries such as paper, plastic, leather, textile, paper, cosmetics, and pharmaceuticals. ${ }^{2}$ The usage of dye on a large scale results in colored effluent being dumped into bodies of water. The textile sector is the one that emits the most dye and aromatic pollutants. ${ }^{3}$ It reduces light penetration and photosynthesis while also degrading the aesthetic value of water bodies. Even very low concentrations of this textile pollution in drinking water can cause physical and genetic changes in people and other living beings. ${ }^{4}$ Acid Yellow 19 is extensively used for dyeing and printing silk and wool fabrics. Wastewater generated from the wool scouring process is a highly polluted waste amongst other textile processes. COD and BOD of this process effluent are approximately $40,000 \mathrm{mg} / \mathrm{L}$ and $120,000 \mathrm{mg} / \mathrm{L} .{ }^{5}$ Wool dyeing waste contains various types of salts (sodium chloride and sodium sulphate used for neutralizing the zeta potential of the fiber), acids (acetic and sulphuric acid for $\mathrm{pH}$ control), and bases (sodium hydroxide for $\mathrm{pH}$ control) and dyes (for dyeing the fiber). Residual dye in combination with the auxiliary chemicals generated colour, dissolved solids and high COD containing effluent. ${ }^{6}$ Once this pollutant bind to the water molecule it results in a complex molecular structure that can resist different environmental conditions, it becomes difficult to treat. Therefore, advanced studies should be conducted to develop economical removal of dye. Adsorption is a process

This is an Open Access article licensed under a Creative Commons license: Attribution 4.0 International (CC- BY). Published by Oriental Scientific Publishing Company @ 2018

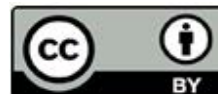


by which molecules from aqueous solutions cling to the surface of the adsorbent. Adsorption happens via electrostatic interactions or Vander Waals forces, depending on the nature of the adsorbents and the chemical structure of the dyes. ${ }^{7}$

Environmentally friendly, economically viable, and simply designable adsorbents for water treatment are in high demand. Adsorption has gained popularity as a sludge-free, clean procedure for removing colour from aqueous solutions. Marine algae are an alternative adsorbent made from biological sources that are abundant around the world. Marine seaweed acts as an adsorbent by bioconversion and biosorption. ${ }^{8}$ Seaweed yields more biochar and has a higher surface area than normal lingo-cellulose biomass in pyrolysis. ${ }^{9}$ Activated carbon application for dye removal is expensive on large scale hence alternative low cost adsorbent with higher pollutant removal rate is high in demand. ${ }^{10}$ Biochar is made from natural wastes such as forest and agricultural biomass, organic waste, and animal waste. ${ }^{11,12}$ Biochar is a carbonaceous, heterogeneous char made by low thermal heating of organic waste/mixture that has been thoroughly degraded. Biochar can be used with a range of applications such as an agent for soil improvement, an avenue for greenhouse gas mitigation, and remediation of particular environmental pollution. ${ }^{13,14}$ Biochar is becoming popular due to its catalytic activity, adsorption effectiveness, high porosity, and large surface area. ${ }^{15}$ Porosity and chemical composition change with changes in feedstocks and the method of heating used. ${ }^{16}$ There are various types of dyes and biochar available in the market but biochar type and dose are the most significant factors while treating the specific type of dye in aqueous media. Present work aimed to study the efficiency of seaweed-based biochar for removal of Acid yellow 19 by adsorption. Different environmental conditions like $\mathrm{pH}$, Dose, contact time and concentration were analyzed to optimize the efficiency of seaweed biochar.

\section{MATERIAL AND METHODS}

\section{Dye and other chemicals used}

Acid Yellow 19 dye and Ulva lactuca seaweed.

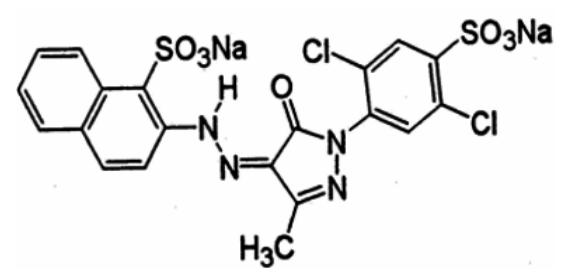

Fig. 1. Acid yellow 19

\section{Preparation of Biochar}

Ulva lactuca seaweed was collected from the Okha coast, Gujarat India. It was washed with tap water to remove the debris. Seaweed was dried in an oven at $60^{\circ} \mathrm{C}$ for moisture removal. After drying seaweed it was crushed using a mortar and pestle and sieved. Seaweed was sieved for $0.71 \mathrm{~mm}$ particle size. Seaweed was kept in a muffle furnace at $450^{\circ} \mathrm{C}$ temperature for $\mathbf{2 0 ~} \mathrm{min}$ for biochar preparation.

\section{The Yield of Biochar}

$\mathrm{Y}=$ Mass after pyrolysis/mass before pyrolysis ${ }^{\star} 100$ $45 \%$ biochar yield was achieved by this method.

\section{Methodology \\ Dye solution preparation \& study}

Different concentrations of dye solutions were prepared using distilled water. To determining the maximum dye wavelength $\left(\lambda_{\max }\right)$ Shimadzu UV-Visible 1800 spectrophotometer was used in the visible range $(400-800 \mathrm{~nm})$. After getting $\lambda_{\max }$ adsorption experiment was conducted to study biochar efficiency.

Adsorption of the Acid Yellow 19 dye on seaweed carbon was tested under various environmental conditions. Experiments began with the addition of $100 \mathrm{~mL}$ of $100 \mathrm{mg} / \mathrm{L}$ dye standard solution to 250 conical flasks in a shaker at 120 RPM. pH optimization was chosen as the first parameter to be study. The maximum dye solution was measured with a Shimadzu UV-Visible 1800 spectrophotometer. The dye elimination rate was estimated using the equation below.

$$
\begin{aligned}
& \text { \%Dye Adsorption }=\left(C_{i}-C_{f}\right)^{*} 100 / C_{i} \\
& \left.q_{e}=\left(C_{i}-C_{f}\right)^{*} V / M\right)
\end{aligned}
$$

Where,

$$
C_{i}=\text { Initial dye concentration, } C_{f}=\text { Final }
$$
dye concentration, $M$ is adsorbent mass $(\mathrm{gm}) q_{e}$ is dye adsorption per gram adsorbent $(\mathrm{mg} / \mathrm{gm}), \mathrm{V}$ is a volume of a sample taken (L). 


\section{RESULT AND DISCUSSION}

\section{Effect of pH on acid dye adsorption}

Batch trial tests were used to determine the effect of $\mathrm{pH}$ on Acid yellow 19 dye adsorption. During the whole experiment $\mathrm{pH}$, was adjusted by $0.2 \mathrm{M}$ $\mathrm{H}_{2} \mathrm{SO}_{4}$ and $0.1 \mathrm{M} \mathrm{NaOH}$. For optimization study $\mathrm{pH}$ range 3-9 was selected for dye adsorption and other parameters like dose, duration and concentration (1 $\mathrm{g}, 2 \mathrm{~h}, 100 \mathrm{mg} / \mathrm{L})$ were remained constant. During experiment, we found that $\mathrm{pH} 3$ was optimum for 90 percent of the Acid Yellow 19 dye adsorption. Fig. 1 indicates that as the $\mathrm{pH}$ rises, the adsorption decreases. Acidic dyes have a negative charge group that aids in interacting with the surface charge of the adsorbent. $\mathrm{pH}$ has a significant impact on the surface charge of an adsorbing surface. ${ }^{17}$ The surface of biochar becomes protonated at low $\mathrm{pH}$. In aqueous conditions with a low $\mathrm{pH}, \mathrm{H}^{+}$ions are more abundant, competing with negatively charged dye group for adsorption of Acid Yellow 19 dye aqueous solution. The excess amount of hydroxyl group in the aqueous media grows as $\mathrm{pH}$ rises, and it is unable to bond effectively with the negative charge of dye surface media. As a result, adsorption is decreasing in our research.

\section{Effect of Dose on Acid dye adsorption}

The dose is an important factor for biosorption optimization. To obtain the optimum dose for dye adsorption, an effect of dosage study was carried out by taking various doses in the range of $1-12 \mathrm{~g}$ of adsorbent and keeping other parameters $(\mathrm{pH} \mathrm{3,2} \mathrm{h}, 100 \mathrm{mg} / \mathrm{L})$ as constants. In our study adsorption decreases with increasing doses due to overlapping of adsorption site, overcrowding of adsorbent particles and instaurations of binding sites. The same results were also observed by Behnajady et al., in 2014. ${ }^{18}$ In our study $100 \mathrm{mg} / \mathrm{L}$ dye solution, $2 \mathrm{~h}$ contact time, $\mathrm{pH} 3$ is taken for analysis.

\section{Effect of contact time on Acid dye adsorption}

The efficiency of Ulva lactuca biochar for stipulated time study has been shown in below Fig. 3. The dye's adsorption rate increases until it reaches a particular limit, after which it becomes stable. In 30 min, the majority of the biosorption was completed. This research found that in the initial stage adsorbent sites are unoccupied and resulting in a stronger driving force of dye on the adsorbent's surface area. The same phenomena were observed by Nemr et al., 2006 and El Sikaily et al., 2006.19

\section{Effect of Concentration on Acid dye adsorption}

The effective concentration of dye for adsorption study was determined by taking different concentrations of dye solution ranging from 100500 concentrations and other parameters as a constant (pH 3,1 g, and 15 minute). To calculate effective concentration, other factors were held constant. It was found that at the beginning of the experiment dye uptake was higher which gradually decreases and become constant till equilibrium was reached. In the initial stage of dye uptake, it was fast due to lower concentration of dye molecule against higher adsorption site of biosorbent in the system, it gradually decreased due to saturation levels of adsorbing media. The same observations were achieved by Tan et al., 2009. ${ }^{20}$

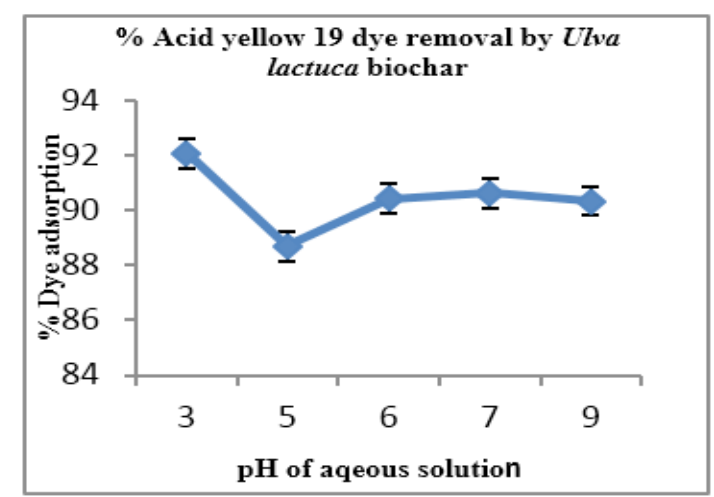

Graph 1: Effect of pH on biosorption

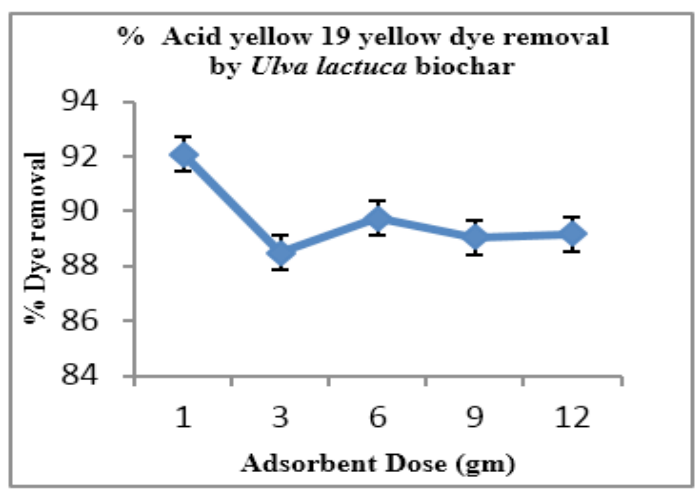

Graph 2: Effect of Dose on biosorption 


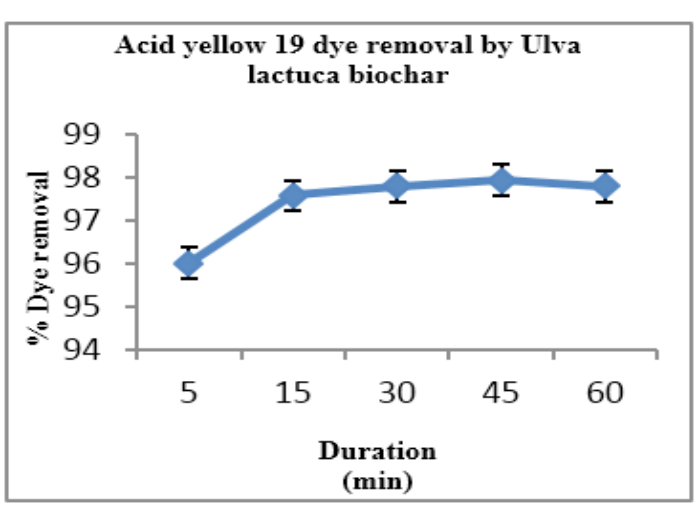

Graph 3: Effect of Duration on biosorption

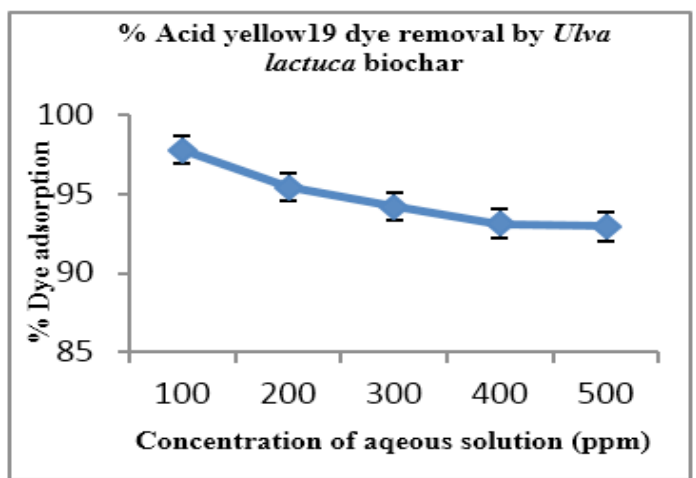

Graph 4: Effect of concentration on biosorptiona

\section{Isotherm study}

The relationship between amounts of adsorbate adsorbed on the biochar surface and concentration of dissolved adsorbate in liquid after treatment is expressed by adsorption isotherm. ${ }^{21}$

\section{Langmuir model \& Freundlich Isotherm}

Langmuir and Freundlich's models are used to estimate the equilibrium of dye adsorbed on seaweed biochar. These two models are the well-known isothermal models for pollutant adsorption on solid adsorbent surfaces. The major difference between the Langmuir Isotherm and Freundlich Isotherm is adsorption behavior. The Langmuir Isotherm assumes monolayer adsorption phenomena while Langmuir assumes heterogeneous adsorption phenomena.

The liner plot of acid yellow 19 dyes isotherm adsorption is shown in Fig. 1. The equilibrium from isotherm models is presented in Table 1.

\section{Langmuir Isotherm}

$c_{e} / q_{e}=\left(1 / q_{0} b\right)+\left(c_{e} / q_{o}\right)$
For Langmuir isotherm graph of $1 / \mathrm{C}_{\mathrm{e}}$ against $1 / q_{e}$ is plotted. Slope and the intercept can be calculated using this graph. Langmuir constant $b$ is calculated using this method.

Table 1: Characteristic of Acid yellow 19 Dye

\begin{tabular}{lll}
\hline Sr. No. & Properties & Characteristic \\
\hline 1 & CAS No & $2220-64-3$ \\
2 & Molecular Formula & $\mathrm{C}_{20} \mathrm{H}_{12} \mathrm{C}_{12} \mathrm{~N}_{4} \mathrm{Na}_{2} \mathrm{O}_{7} \mathrm{~S}_{2}$ \\
3 & Molecular Weight & 601.35 \\
4 & Solubility & $50 \mathrm{~g} / \mathrm{L}$ water solubility \\
5 & Application & Dyeing and printing of \\
& & Wool and silk \\
\hline
\end{tabular}

\section{Freundlich Isotherm}

$\log q_{e}=\log K_{f}+1 / n \log C_{e}$

Freundlich Isotherm was obtained by plotting $\log C e$ versus $\log q_{e} \cdot K_{f}$ and $n$ in graph obtained by intercept and slope of graph respectively.
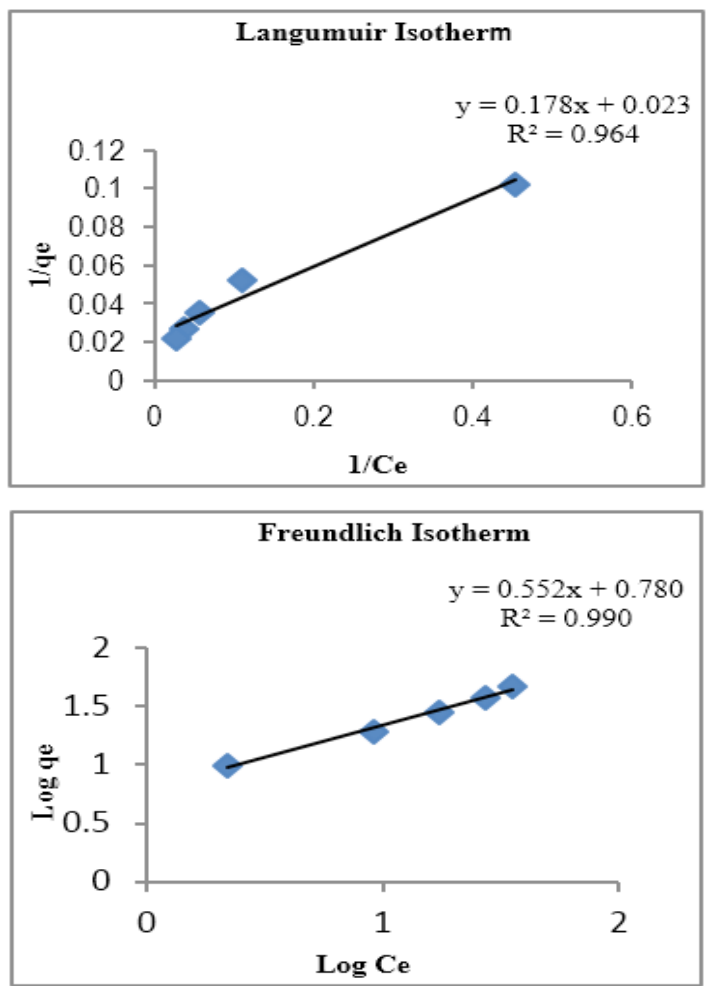

Graph 5 \& 6: Langumuir \& Freundlich Isotherm

\begin{tabular}{lccccc}
\hline Langmuir model & \multicolumn{5}{c}{ Freundlich model } \\
\hline $\mathrm{Q}_{\max }$ & $\mathrm{K}_{\mathrm{L}}$ & $\mathrm{R}^{2}$ & $\mathrm{n}$ & $\mathrm{K}_{\mathrm{F}}$ & $\mathrm{R}^{2}$ \\
43.48 & 0.129 & 0.964 & 1.8 & 6.025 & 0.990 \\
\hline
\end{tabular}


Results achieved using biosorption of Acid yellow 19 dye using Ulva lactuca carbon strongly suggested that Ulva lactuca carbon is economical and it can remove acid yellow 19 dye from aqueous solution. The data showed that the adsorption of Acid yellow 19 dyes is more favourable to Freundlich than the Langmuir isotherm, implying that the entire process is heterogeneous surface adsorption.

\section{SEM analysis}

Scanning electron microscopy (SEM) was used to analyze the surface morphology of the activated carbons, and SEM micrographs were taken before and after dye adsorption. The presence of white aggregates on the surface of the treated $U$. lactuca can be seen in the SEM micrograph image, indicating that Dye particles were deposited on the carbon surface.

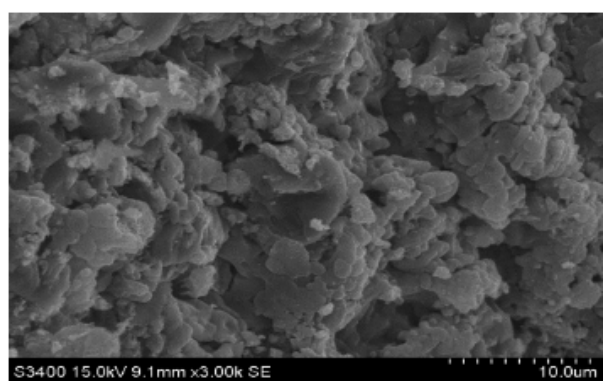

Image 1: SEM before dye adsorption

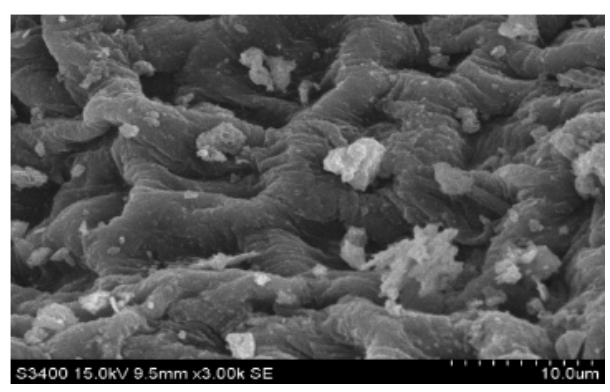

Image 2: SEM after dye adsorption

\section{FTIR Study}

FTIR spectra were used to analyse the functional group's identification in dried and metalloaded biochar. When comparing two graphs, there is a shift in the wave number of major peaks this changes proves dye adsorption on carbon surface. The rise in the width of the peak at $3194.3 \mathrm{~cm}^{-1}$ is due to the dye molecule interaction. In the raw seaweed 3485.1 is due to the stretching of $\mathrm{N}-\mathrm{H}$ bond. Raw biochar has $\mathrm{O}-\mathrm{H}$ bond stretching at 3242.8 wavelengths, which shifts to 3194.3 after lead treatment. 1080.9 wavelength in both graph indicates stretching of C-O bond due to primary alcohol in the biochar.

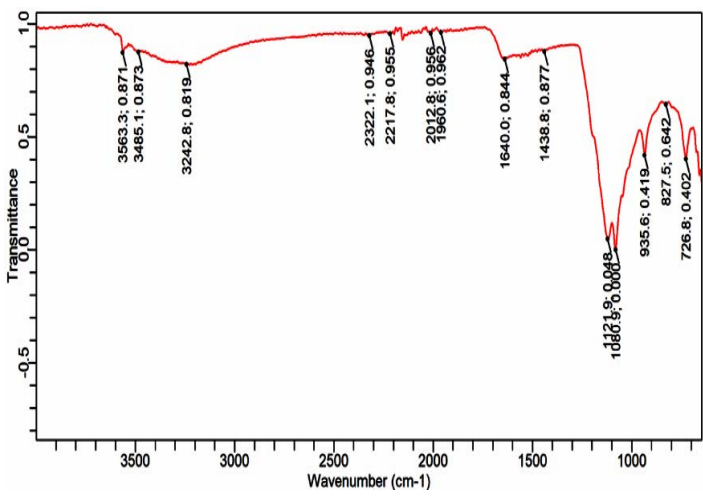

Graph 7: FTIR of biochar before Acid 19 dye biosorption

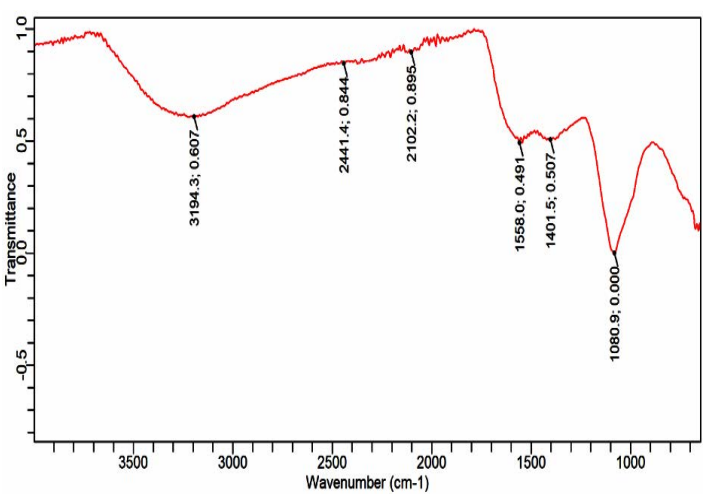

Graph 8: FTIR of biochar after Acid 19 dye biosorption

\section{CONCLUSION}

For the adsorption of Acid yellow 19 dyes from an aqueous solution, Ulva lactuca carbon was prepared and characterized in this research. SEM study revealed the presence of porosity. FTIR was used to show the chemical functional groups. The research revealed that variables such as $\mathrm{pH}$, contact time, initial dye concentration, and adsorbent dosage are all important factors to consider on the uptake capacity. At pH 3 the maximum capacity for Acid dye 19 uptake was attained. The experiments demonstrated the potential of seaweed derived carbon as an efficient low-cost adsorbent for removal of Acid yellow 19 dye.

\section{ACKNOWLEDGMENT}

The authors wish to thanks V.P. \& R.P.T.P Science College for research support.

\section{Conflict of interest}

The authors declare that there is no conflict of interest. 


\section{REFERENCES}

1. King, P.; Kumar, P. V.; and Prasad, V. S. R. K., Studies on Adsorption isotherms for removal of Fluorides using conventional and nonconventional adsorbents. Journal of Industrial Pollution Control., 2005, 21(1), 155-162.

2. Matheickal, J. T.; lyengar, L.; and Venkobachar. C.; Kes, J., Sorption and desorption of Cu(II) by Ganoderma lucidum, Water Pol. Res. J., Canada., 1991, 26, 187.

3. Huang, W.; Wang, S.; D. Li., Polymers and polymer composites for adsorptive removal of dyes in water treatment, Sustainable polymer composites and nanocomposites, Springer nature., 2019, 519-556.

4. Ullah, S.; Hashmi, M.; Hussain, N.; Ullah, A.; Sarwar, M.N.; Saito Y., Stabilized nanofibers of polyvinyl alcohol (PVA) crosslinked by unique method for efficient removal of heavy metal ions, J of Water Process Eng, J of Water Process Eng., 2020, 33, 101-111.

5. Chris, T.; J.R., and Bateup, B.O., Developments in Wool Scouring-an Australian Perspective. Wool Science Review, Wool Science Review., 1987, 64, 25-43.

6. Isk, M.; Sponza D. T., Biological treatment of acid dyeing wastewater using a sequential anaerobic/aerobic reactor system, Enzyme and Microbial Technology, Enzyme and Microbial Technology., 2006, 38, 887-892.

7. Ghadah, M.; Senani, A., and Nada, S.; AlKadhi, Studies on Adsorption of Fluorescein Dye from Aqueous Solutions Using Wild Herbs, International Journal of Analytical Chemistry., 2020, 1, 1-9.

8. Nemr A. E.; Abdelwahab, O.; Khaled, A. and Sikaily, A. E., Biosorption of Direct Yellow 12 from aqueous solution using green alga Ulva lactuca, Ecol., 2006, 22, 253-66.

9. Roberts, D. A.; Paul N. A.; Dworjanyn, A. S., Michael I. Bird \& Rocky de Nys., Biochar from commercially cultivated seaweed for soil amelioration, Scientific Reports., 2015, 5, 1-6.

10. Eder, L.; Royer, B.; Julio, C.; Vaghetti, P; Nathália, S., Application of Brazilian pine-fruit shell as a biosorbent to removal of reactive red 194 textile dye from aqueous solution. Kinetics and equilibrium study, $J$ Hazard Mater., 2008, 155(3), 536-550.

11. Xu, Y.; Luo, G.; He, S.; Deng, F.; Pang, Q.;
Xu, Y.; Yao, H., Efficient removal of elemental mercury by magnetic chlorinated biochars derived from co-pyrolysis of $\mathrm{Fe}(\mathrm{NO} 3) 3$-laden wood and polyvinyl chloride waste., Fuel., 2019, 239, 982-990.

12. Yang, H.; Ye, S.; Zeng, Z.; Zeng, G.; Tan, X.; Xiao, R.; Wang, J.; Song, B.; Du, L.; Qin, Utilization of biochar for resource recovery from water: A review., M. Chem. Eng. J., 2020, 397.

13. Chen, B.; Chen, Z.; Lv. S., A novel magnetic biochar efficiently sorbs organic pollutants and phosphate, Bioresour. Technol., 2011, 102, 716-723.

14. Liu, Y., Characterization of bio-char from pyrolysis of wheatstraw and its evaluation on methylene blue adsorption, Desalination and Water Treatment., 2013, 46, 115-123.

15. Dai, Y.; Zhang, N.; Xing, C.; Cui, Q.; Sun, Q., The adsorption, regeneration and engineering applications of biochar for removal organic pollutants: A review, Chemosphere., 2019, 223, 12-27.

16. Ronsse, F.; Hecke SV.; Dickinson, D., Prins, W., Production and characterization of slow pyrolysis biochar: Influence of feedstock type and pyrolysis conditions, GCB-Bioenergy., 2013, 5, 104-115.

17. Xue, S. W.; Yin, Z.; Yu J.; Sun C., The removal of basic dyes from aqueous solutions using agricultural by-products, J Hazard Mater., 2008, 157(2-3), 374-385.

18. Behnajady, M.A.; Bimeghdar S., Synthesis of mesoporous $\mathrm{NiO}$ nanoparticles and their application in the adsorption of $\mathrm{Cr}(\mathrm{VI})$, Chem. Eng. J., 2014, 239, 105-113.

19. Sikaily, A. E.; Khaled, A.; Nemr, A. E.; and Abdelwahab, O., Removal of Methylene Blue from aqueous solution by marine green alga Ulva lactuca, Chem. Ecol., 2006, 22, 149-157.

20. Tan, Pei-Ling.; Wong, Ching-Lee.; SiewTeng, Ong.; Ling Hii Siew., Equilibrium and Kinetic Studies for Basic Yellow 11 Removal by Sargassum binderi, Journal of Applied Sciences., 2009, 9(17),3005-3012.

21. Stepniewska, Z.; Bucior, K.; Bennicilli, R., The effects of $\mathrm{MnO}_{2}$ on sorption and oxidation of Cr(III) by soils, Geoderma., 2004, 122, 291-296. 